DOI: $10.15593 / 2224-9982 / 2021.65 .11$

УДК 629.7.036.22

Я.Э. Богомолов, В.И. Малинин

Пермский национальный исследовательский политехнический университет

Пермь, Россия

\author{
ОПРЕДЕЛЕНИЕ СРЫВНЫХ ХАРАКТЕРИСТИК В ФОРКАМЕРЕ \\ КОМБИНИРОВАННОГО ПРЯМОТОЧНОГО ВОЗДУШНО-РЕАКТИВНОГО \\ ДВИГАТЕЛЯ НА ПОРОШКООБРАЗНОМ АЛЮМИНИЕВОМ ГОРЮЧЕМ \\ С УЧЕТОМ ТОРМОЖЕНИЯ ВОЗДУХА В ВОЗДУХОЗАБОРНОМ УСТРОЙСТВЕ
}

\begin{abstract}
Рассматривается комбинированный прямоточный воздушно-реактивный двигатель на порошкообразном алюминиевом горючем. Прототипом послужил комбинированный ракетно-прямоточный двигатель на твердом топливе. Приведены достоинства рассматриваемого двигателя. Рассмотрен пример горения мелкодисперсного порошка алюминия, из которого следует, что начальная температура порошка алюминия повлияет на срывные характеристики в форкамере. Определены следующие характеристики ПВРД на ПАГ: температура торможения воздуха в воздухозаборном устройстве, температура смеси порошка алюминия и заторможенного потока воздуха, коэффициент избытка воздуха, срывные характеристики в форкамере с учетом температур торможения воздуха. Все параметры определены для значений высоты эксплуатации двигателя, равных 0,5; 10 и 18 км. Проведено сравнение предельных скоростей распространения пламени при стандартных условиях и при набегающем потоке воздуха. С опорой на полученные значения характеристик определен интервал значений коэффициента отбора воздуха из ВЗУ в форкамеру ПВРД на ПАГ, соответствующий максимально возможным областям рабочих параметров двигателя. С использованием полученных значений характеристик процесс горения порошкообразного алюминия в форкамере прямоточного воздушно-реактивного двигателя проходит без срыва пламени, что исключает нестабильную работу двигательной установки в целом. Использование порошкообразного алюминия дает возможность регулирования тяги в широком диапазоне значений, а высокая начальная температура воздуха, поступающего в форкамеру, ведет к многократному включению и выключению двигателя. На основе имеющихся данных сделан вывод, что рассматриваемый вид двигателей подходит для боевых ракет различного класса, но более всего для ракет авиационного базирования.

Ключевые слова: комбинированный ракетно-прямоточный двигатель на твердом топливе, прямоточный воздушно-реактивный двигатель на порошкообразном алюминиевом горючем, фоокамера, срывные характеристики, области рабочих параметров, коэффициент отбора воздуха, коэффициента избытка воздуха, температура торможения воздуха, предельные скорости распространения пламени, воздухозаборное устройство.
\end{abstract}

\title{
Y.E. Bogomolov, V.I. Malinin
}

Perm National Research Polytechnic University

Perm, Russian Federation

\section{DETERMINATION OF BREAKING CHARACTERISTICS}

\section{IN THE PRE-COMBUSTION CHAMBER OF A COMBINED RAMJET ENGINE} ON A POWDERED ALUMINUM FUEL TAKING INTO ACCOUNT AIR BRAKING IN AIR INTAKE DEVICE

The paper considers a combined ramjet engine powered by powdered aluminum fuel . The prototype was a combined solid-fuel ramjet engine. The advantages of the engine under consideration are given. An example of the combustion of finely dispersed aluminum powder is considered, from which it follows that the initial temperature of the aluminum powder will affect the stall characteristics in the pre-chamber. The following characteristics of the PAF ramjet were determined: the temperature of air stagnation in the air intake device, the temperature of the mixture of aluminum powder and the stalled air flow, the excess air ratio, and the stall characteristics in the pre-chamber taking into account the air stagnation temperatures. All parameters are determined for engine operating altitudes equal to $0.5,10$ and $18 \mathrm{~km}$. A comparison is made of the limiting flame propagation velocities under standard conditions and with an incident air flow. Based on the obtained values of the characteristics, the interval of values of the coefficient of air sampling from the inlet to the pre-chamber of the ramjet engine on the PAF was determined, corresponding to the maximum possible areas of the engine operating parameters. Using the obtained values of characteristics, the combustion process of powdered aluminum in the pre-chamber of a ramjet engine takes place without flame blowout, which excludes unstable operation of the propulsion system as a whole. The use of powdered aluminum makes it possible to regulate the thrust in a wide range of values, and a high initial temperature of the air entering the pre-chamber for repeated switching on 
and off of the engine. Based on the available data, the type of engines under consideration is suitable for combat missiles of various classes, but the most suitable for aircraft-based missiles.

Keywords: combined rocket-ramjet engine on solid fuel, ramjet engine on powdery aluminum fuel, pre-combustion chamber, breaking characteristics, areas of operating parameters, air extraction coefficient, excess air coefficient, air stagnation temperature, limiting flame propagation velocities, air intake device.

В последние годы в нашей стране и за рубежом интенсивно развивается тактическое ракетное вооружение. Развитие такого вооружения является радикальным средством повышения эффективности зенитно-ракетных систем, авиационных боевых и ракетно-артиллерийских комплексов, играющих определяющую роль в локальных конфликтах. Отсутствие возможности существенного совершенствования ракетного вооружения за счет модернизации широко применяемых РДТТ, которые практически достигли предела своего совершенства, привлекает особое внимание к двигательным установкам, энергетические возможности которых могут быть существенно улучшены за счет использования атмосферного воздуха. К наиболее перспективным для высокоскоростных летательных аппаратов с внутриатмосферной зоной эксплуатации относятся комбинированные двигатели с прямоточными воздушно-реактивными двигателями и ракетно-прямоточные двигатели на твердом топливе [1-12]. Интерес к комбинированным двигательным установкам обусловлен широкой областью их применения, в которой прямоточные воздушно-реактивные двигатели (ПВРД) наиболее экономичны по сравнению с ракетными двигателями на твердом топливе, при высоком уровне удельного импульса тяги. Применение таких двигателей достаточно сильно повлияет на боевую эффективность летательных аппаратов в целом.

В данной работе исследуются процессы в форкамере (ФК) комбинированного прямоточного воздушно-реактивного двигателя (КПВРД) на порошкообразном алюминиевом горючем (ПАГ). Целью работы является определение срывных характеристик и интервала значений коэффициента отбора воздуха в ФК с учетом торможения воздуха в воздухозаборном устройстве (ВЗУ). Исходными данными послужили области рабочих параметров ПВРД на ПАГ для значений высоты полета 0,5; 10 и 18 км, которые рассмотрены в работе [11].
В первую очередь определялись срывные характеристики в ФК с учетом подогрева воздуха при торможении в ВЗУ в зависимости от коэффициента избытка воздуха для разных значений высоты полета ЛА ( $H=0,5 ; 10,18$ км). Температура торможения в ВЗУ ПВРД при больших скоростях потока $(M>4)$ достигает значения более 1200 К. В статьях [13-15] описаны исследования процессов горения мелкодисперсного порошка алюминия в воздухе, в результате которых было выявлено, что при больших начальных температурах аэровзвеси скорость распространения пламени существенно выше. На рис. 1 представлена зависимость скорости распространения пламени от начальной температуры аэровзвеси частиц алюминия [13].

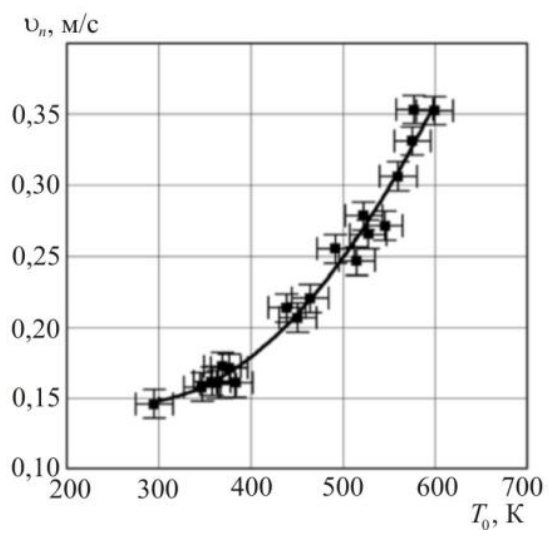

Рис. 1. График зависимости распространения пламени от начальной температуры аэровзвеси частиц алюминия [13]

Определим на основе теплового баланса температуру смеси порошка алюминия и заторможенного воздуха в ФК. Температура торможения воздуха рассчитывалась по формуле

$$
T_{H}^{*}=T_{H}\left(1+\frac{k-1}{2} \cdot M^{2}\right)
$$

где $T_{H}^{*}$ - температура торможения; $T_{H}$ - температура воздуха на высоте $H$; $M$ - число Маха; $k$ - показатель адиабаты воздуха.

Тогда для определения коэффициента избытка воздуха в $Ф К \alpha_{\phi к}$ использовалась 
формула, где значения коэффициента избытка воздуха в камере сгорания $\left(\alpha_{\phi к}=1 \ldots 7\right)$ выбраны из работы [11], а коэффициент отбора воздуха из ВЗУ в ФК $\left(K_{\phi к}\right)$ задавался как

$$
\alpha_{\phi \kappa}=\alpha_{\text {кс }} K_{\phi \kappa} .
$$

Далее определим температуру смеси порошка алюминия и заторможенного воздуха $\left(T_{\mathrm{c}}\right)$ :

$$
T_{\mathrm{c}}=\frac{\left(T_{\mathrm{Al}}+T_{H}^{*} \alpha_{\phi \kappa}\right)}{\left(1+\alpha_{\phi \kappa}\right)} .
$$

Здесь $T_{\mathrm{Al}}$ - температура порошка алюминия при стандартных условиях (288 К).

По результатам расчетов $\left(T_{\mathrm{c}}\right)$ построены графики зависимости температур смеси порошка алюминия и заторможенного воздуха от коэффициента избытка в ФК (рис. 2). Уменьшение температур аэровзвеси относительно температуры торможения потока обусловлено подогревом алюминия во время перемешивания его с воздухом, отобранным из ВЗУ, в ФК.
Значения скоростей распространения пламени в форкамере рассчитывались на основе формулы, полученной в работе [13]:

$$
\mathrm{v}_{\text {фк }}=\mathrm{v}_{\mathrm{cp}}\left(\frac{T_{\mathrm{c}}}{T_{\mathrm{Al}}}\right)^{1,5},
$$

где $v_{\mathrm{cp}}$ - скорость распространения пламени при стандартных условиях без учета подогрева воздуха при торможении, описанная в работах $[5,12]$.

По результатам расчетов $v_{\phi к}$ построены графики зависимости предельных скоростей распространения пламени в форкамере КПВРД на ПАГ от коэффициента избытка воздуха для аналогичных значений высоты полета ЛА (рис. 3). На рис. 3 добавлена зависимость скорости распространения пламени без учета подогрева воздуха при торможении $[5,12]$ для сравнения с полученными результатами.
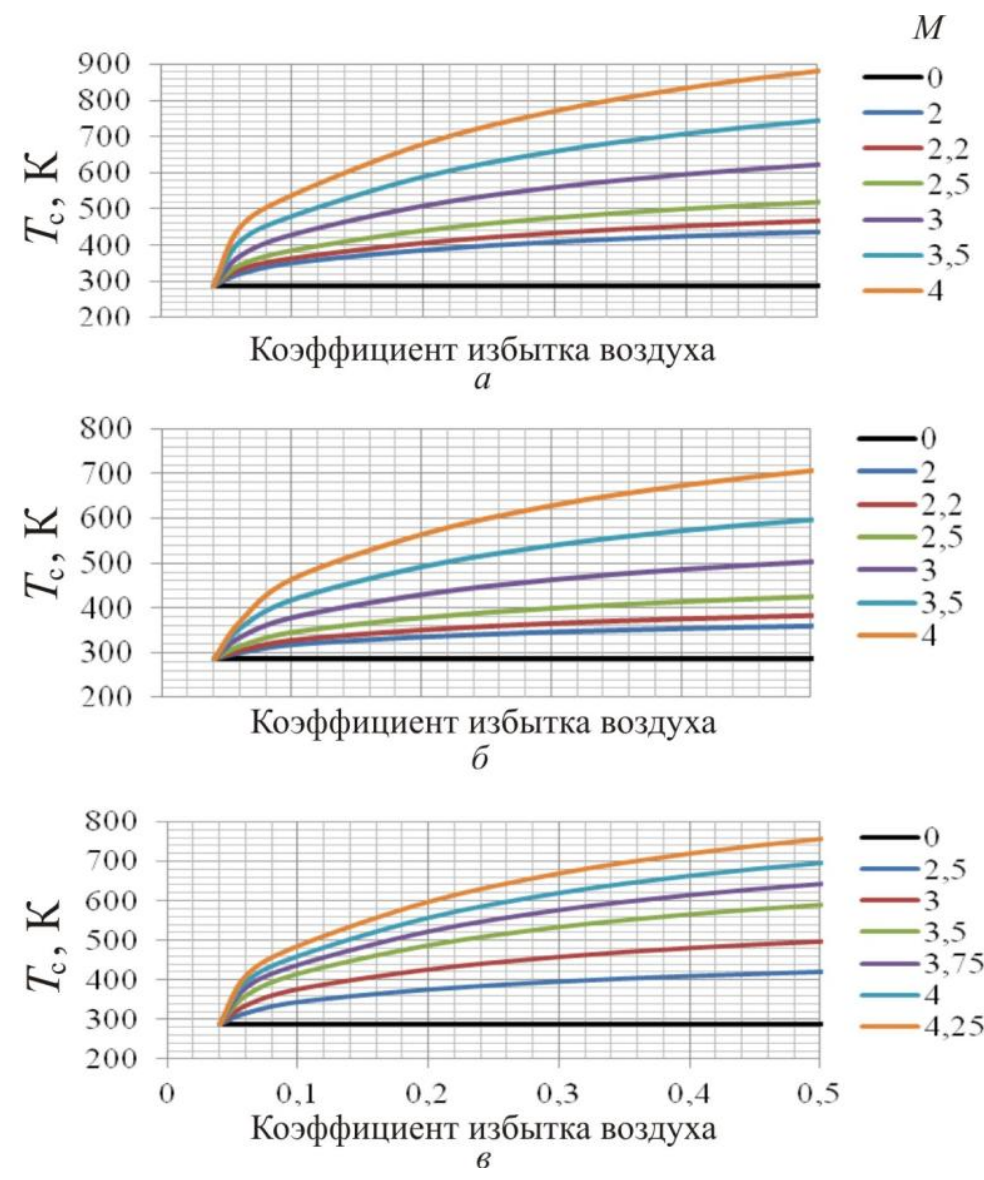

Рис. 2. Графики зависимости температур смеси порошка алюминия и заторможенного потока воздуха от коэффициента избытка в ФК: $a-H=0,5 ; \sigma-H=10$, в $-H=18$ км 


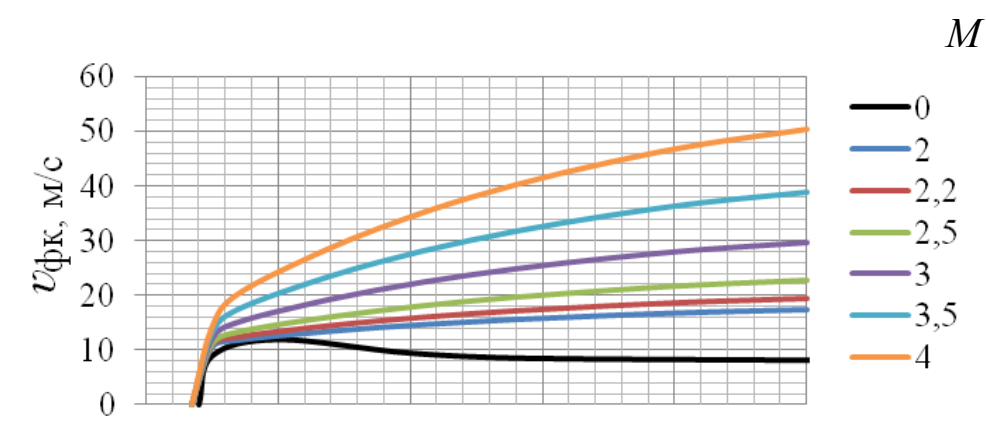

Коэффициент избытка воздуха

$a$

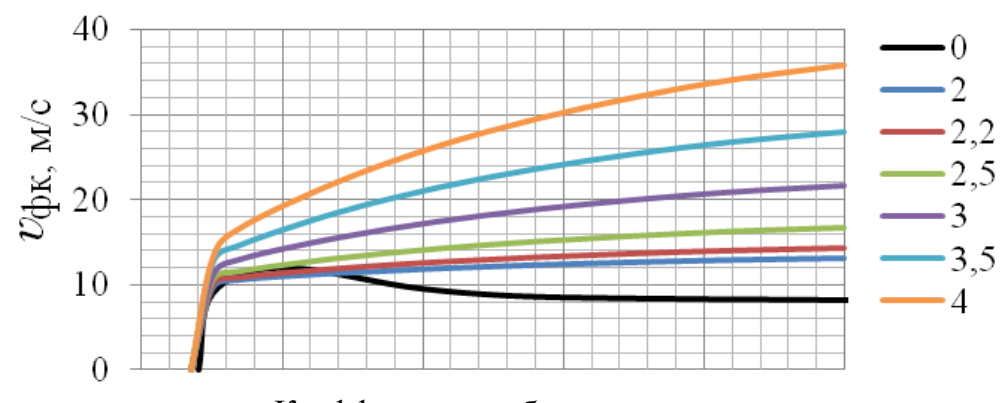

Коэффициент избытка воздуха

6

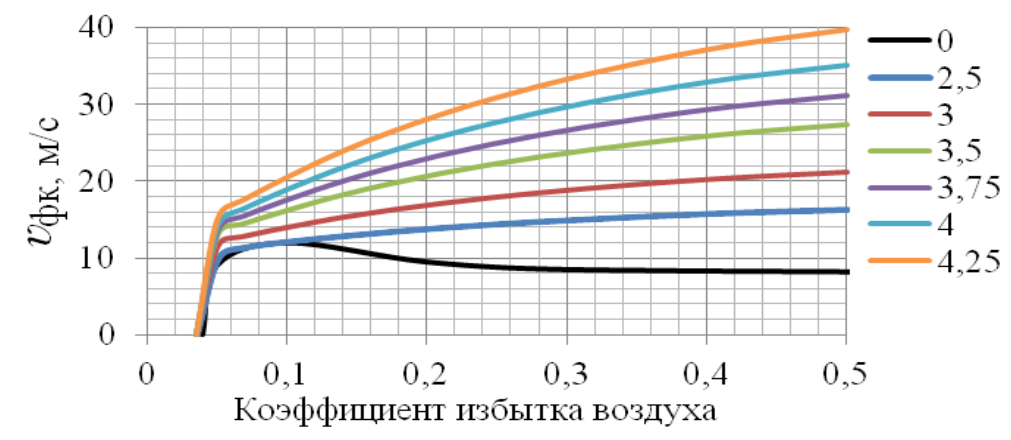

B

Рис. 3. Графики зависимости предельных скоростей распространения пламени от избытка коэффициента воздуха в ФК: $a-H=0,5 ; \sigma-H=10 ; в-H=18$ км

Из рис. 2 следует, что повышение температуры аэровзвеси части алюминия в ФК приводит к увеличению предельных скоростей срыва пламени. Вследствие этого крайние точки областей рабочих параметров [11] полностью попадают в диапазоны значений скоростей распространения пламени.

На втором этапе необходимо определить диапазон значений коэффициента отбора воздуха в ФК. Данный коэффициент устанавливается исходя из условия, что скорость потока областей рабочих параметров [12] не превышает предельных скоростей срыва пламени. Исходя из этого, выявлено, что для получения максимального значения диапазона работы двигателя из ВЗУ необходимо отбирать в ФК $10 \%$ от общего захватываемого воздуха. С учетом полученного значения были пересчитаны скорости распространения пламени в ФК при различных скоростях полета ЛА $(M=2 \ldots 4,25)$. По результатам расчетов построены графики предельных скоростей распространения пламени в ФК комбинированного ПВРД на ПАГ в зависимости от коэффициента избытка воздуха для аналогичных значений высоты полета ЛА (рис. 4). На рис. 4 нанесены крайние точки областей рабочих параметров (" . * *) с учетом выбранного значения коэффициента отбора воздуха $K_{\phi \mathrm{K}}=0,1$. 


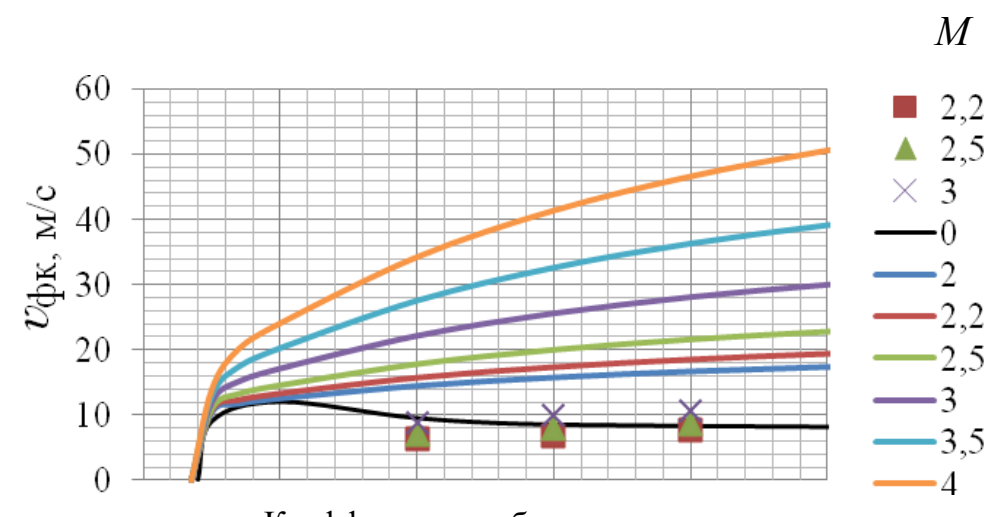

Коэффициент избытка воздуха

$a$

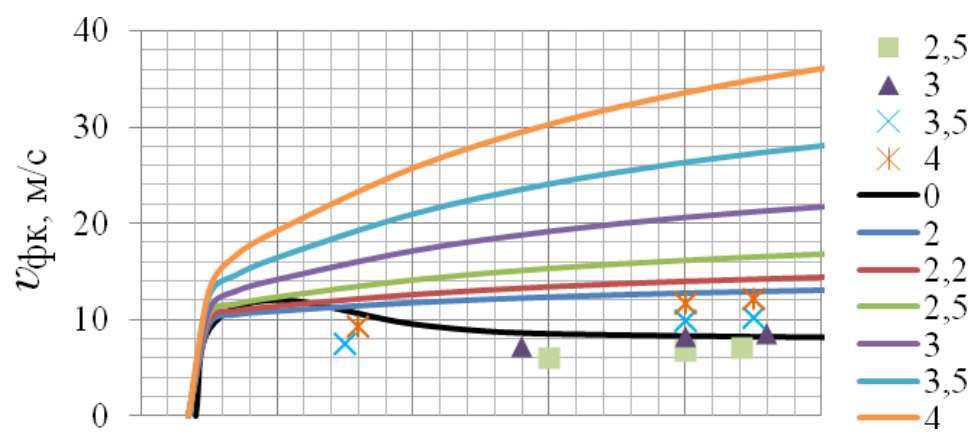

Коэффициент избытка воздуха

б

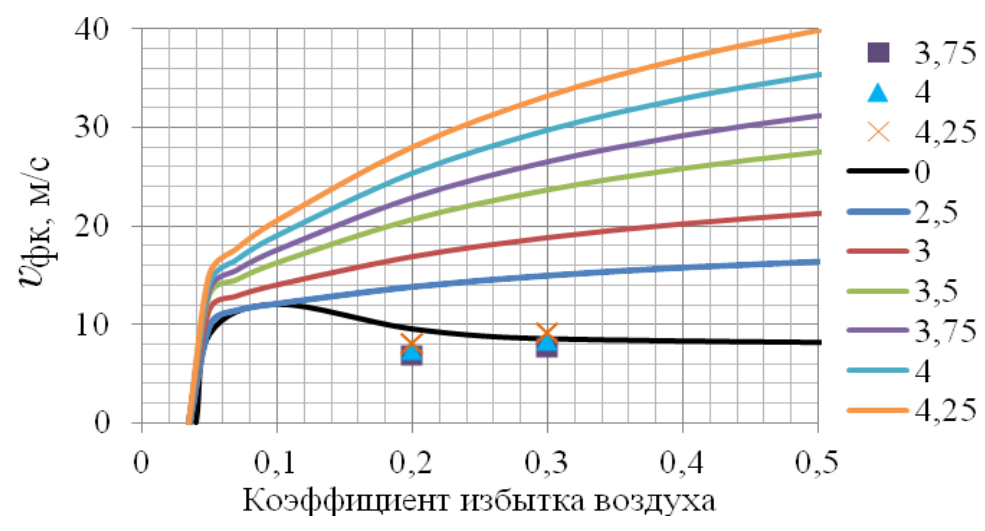

Рис. 4. Графики зависимости предельных скоростей распространения пламени от избытка коэффициента воздуха в ФК с крайними точками областей рабочих параметров: $a-H=0,5 ; \sigma-H=10 ; в-H=18$ км

На рис. 3, 4 показано, что скорость распространения пламени в ФК обладает достаточно большим диапазоном значений. Вследствие этого летательный аппарат с ПВРД на ПАГ будет обладать высокой степенью регулирования тяги, что приведет к повышению его маневренности.

\section{Выводы}

1. Увеличение скорости полета ЛА приводит к значительному повышению темпера- туры заторможенного потока воздуха в ВЗУ $\left(T_{H}{ }^{*}=500 \ldots 1200 \mathrm{~K}\right.$, см. рис. 2$)$ и скорости распространения пламени в форкамере $\left(v_{\phi к}=10 \ldots 50 \mathrm{M} / \mathrm{c}\right.$, см. рис. 3,4$)$, что приводит к большей устойчивости процесса в форкамере с учетом подогрева алюминиево-воздушной смеси, чем без учета подогрева.

2. Увеличение полноты сгорания в камере сгорания связано с тем, что процесс в ФК протекает при более высоких значениях коэф- 
фициента избытка воздуха $\alpha_{\phi к}$. При высоких значениях ( $\alpha_{\phi к}>0,3$, см. рис. 4) частицы алюминия испаряются, и в КС поступает не конденсированное, а газообразное горючее.

3. Увеличение температуры смеси порошка алюминия и заторможенного потока воздуха $T_{\text {c }}$ позволяет повысить коэффициент отбора воздуха из воздухозаборного устройства в форкамеру $\left(K_{\phi к}\right)$ от 7 до $10 \%$ (см. рис. 4).
4. На основе вышеперечисленного можно сделать вывод, что прямоточный воздушнореактивный двигатель на порошкообразном алюминиевом горючем способен регулировать тягу в широких пределах. Летательный аппарат с ПВРД на ПАГ будет обладать более высокой степенью маневренности, что повысит его боевую эффективность.

\section{Библиографический список}

1. Сорокин В.А. Конструкция и проектирование комбинированных ракетных двигателей на твердом топливе: учеб. для вузов. - М.: Изд-во МГТУ им. Н.Э. Баумана, 2014. - 303 с.

2. Теоретические основы анализа и синтеза комбинированных ракетных двигателей на твердых и пастообразных топливах / Б.В. Обносова, В.А. Сорокин, Л.С. Ясновский [и др.]; под ред. Б.В. Обносова, В.А. Сорокина. - М.: Дашков и Кㅇ 2012. -244 с.

3. Интегральные прямоточные воздушно-реактивные двигатели на твердых топливах. Основы теории и расчет / В.Н. Александров, В.М. Быцкевич, В.К. Верхломов [и др.]; под ред. Л.С. Ясновского. - М.: Академкнига, 2006. - $343 \mathrm{c}$.

4. Орлов Б.В. Основы проектирования ракетно-прямоточных двигателей: учеб. пособие для вузов. М.: Машиностроение, 1967. - 423 с.

5. Малинин В.И. Внутрикамерные процессы в установках на порошкообразных металлических горючих / УрО РАН. - Екатеринбург; Пермь, 2006. - 262 с.

6. Experimental characterization of a solid-fuel ramjet combustor at flight-relevant conditions / J.V. Evans, W.C.B. Senior, R.M. Gejji, C.D. Slabaugh // AIAA Propulsion and Energy. - August 2020. - P. 24-28.

7. Thermodynamic performance analysis of ramjet engine at wide working conditions / Ou Min, $\mathrm{Yan} \mathrm{Li}$, Tang Jing-feng, Huang Wei, Chen Xiao-qian // Acta Astronautica. - March 2017. - Vol. 132. - P. 1-12.

8. Leonardo C.F., Shynkarenko O. Experimental and analytical study of the cold flow inside a ramjet test engine // Journal of Aerospace Technology and Management. - 2020. - Vol. 12, iss se. - P. 25-37.

9. Investigation on the effect of diaphragm on the combustion characteristics of solid-fuel ramjet / Gong Lunkun, Chen Xiong, Yang Haitao, Li Weixuan, Zhou Changsheng // Acta Astronautica. - October 2017. Vol. 139. - P. 449-462.

10. Liwei Zhang, Hong-Gye Sung, Yang V. Liwei zhang flow and flame dynamics in a hydrocarbon-fueled dual-combustion ramjet engine // American Institute of Aeronautics and Astronautics Country of Publication. - Orlando, Reston, VA USA, 2020. - $11 \mathrm{p}$.

11. Богомолов Я.Э., Малинин В.И. Определение области рабочих параметров прямоточного воздушно-реактивного двигателя на порошкообразном алюминиевом горючем на основе характеристик ракетнопрямоточного двигателя на твердом топливе летательного аппарата «Метеор» // Вестник Пермского национального исследовательского политехнического университета. Аэрокосмическая техника. - 2017. - № 4 (51). C. 58-67.

12. Малинин В.И., Коломин Е.И., Антипин И.С. Воспламенение и горение аэровзвеси алюминия в реакторе высокотемпературного синтеза порошкообразного оксида алюминия // Физика горения и взрыва. 2002. - T. 38, № 5. - C. 41-51.

13. Скорость стационарного пламени в газовзвесях алюминия / Н.Д. Агеев, С.В. Горошин, А.Н. Золотко, Н.И. Полетаев // Горение гетерогенных и газовых систем. - Черноголовка, 1989. - С. 83-85.

14. Полетаев Н.И. Связь скорости распространения пылевого пламени с режимом горения частиц горючего // Физика горения и взрыва. - 2016. - Т. 52, № 6. - С. 60-69.

15. Егоров А.Г. О скорости распространения пламени в аэровзвеси частиц алюминия // Физика горения и взрыва. - 2020. - Т. 56, № 1. - С. 48-58.

\section{References}

1. Sorokin V.A. Konstrukciya i proektirovanie kombinirovannyh raketnyh dvigatelej na tverdom toplive: uchebnik dlya vuzov [Design and design of combined solid propellant rocket engines: textbook for universities]. Moscow: MGTU named by N. EH. Bauman, 2014. 303 p.

2. Obnosov B.V., Sorokin V.A., Yasnovsky L.S. [et al] Teoreticheskie osnovy analiza i sinteza kombinirovannyh raketnyh dvigatelej na tverdyh i pastoobraznyh toplivah [Theoretical foundations of analysis and 
synthesis of combined rocket engines on solid and pasty fuels]. Ed. B.V. Obnosov, V.A. Sorokin. M.: Publishing and Trade Corporation "Dashkov and K", 2012. 244 p.

3. Aleksandrov V.N., Bytskevich V.M., Verkhlomov V.K. [et al] Integralnye pryamotochnye vozdushnoreaktivnye dvigateli na tverdyh toplivah. Osnovy teorii i raschet [Integral ramjet engines on solid fuels. Fundamentals of theory and calculation]. Ed. L.S. Yanovsky. M.: Akademkniga, 2006.

4. Orlov B.V. Osnovy proektirovaniya raketno-pryamotochnyh dvigatelej [Fundamentals of designing ramjet engines: a textbook for universities]: M .: Publishing house "Mechanical engineering", 1967. 423p.

5. Malinin V.I. Vnutrikamernye processy v ustanovkah na poroshkoobraznyh metallicheskih goryuchih [Intra-chamber processes in installations on powdered metal fuels]. Ekaterinburg-Perm: Ural Branch of the Russian Academy of Sciences, 2006. 262 p.

6. Jay V. Evans, William C. B. Senior, Roban M. Gejji, Carson D. Slabaugh Experimental Characterization of a Solid-Fuel Ramjet Combustor at Flight-Relevant Conditions. AIAA Propulsion and Energy, august 2020, pp. 24-28.

7. Ou Min, Yan Li, Tang Jing-feng, Huang Wei, Chen Xiao-qianThermodynamic performance analysis of ramjet engine at wide working conditions. Acta Astronautica. March 2017, vol. 132, pp. 1-12.

8. Leonardo C.F., O. Shynkarenko Experimental and Analytical Study of the Cold Flow Inside a Ramjet Test Engine. Journal of Aerospace Technology and Management, 2020, vol. 12, iss se, pp. 25-37.

9. Gong Lunkun, Chen Xiong, Yang Haitao, Li Weixuan, Zhou Changsheng. Investigation on the effect of diaphragm on the combustion characteristics of solid-fuel ramjet. Acta Astronautica. Oct. 2017, vol. 139, p. 449-462.

10. Liwei Zhang, Hong-Gye Sung, Yang, V. Liwei Zhang Flow and Flame Dynamics in a Hydrocarbonfueled Dual-Combustion Ramjet Engine. 2020, 11 pp. Publisher: Reston, VA USA; Orlando, FL USA: American Institute of Aeronautics and Astronautics Country of Publication: USA

11. Bogomolov I.E., Malinin V.I. Opredelenie oblasti rabochih parametrov pryamotochnogo vozdushnoreaktivnogo dvigatelya na poroshkoobraznom alyuminievom goryuchem na osnove harakteristik raketnopryamotochnogo dvigatelya na tverdom toplive letatel'nogo apparata «Meteor» [Determination of the range of operating parameters of a ramjet engine powered by powdered aluminum fuel based on the characteristics of a solid fuel ramjet engine of the Meteor aircraft]. Vestnik of PNRPU. Aerospace Engineering, 2017, p. 58-67.

12. Malinin V.I., Kolomin E.I., Antipin I.S. Vosplamenenie i gorenie aerovzvesi alyuminiya v reaktore vysokotemperaturnogo sinteza poroshkoobraznogo oksida alyuminiya [Ignition and combustion of aluminum air suspension in the reactor for high-temperature synthesis of powdered aluminum oxide]. Physics of Combustion and Explosion. 2002. Vol. 38, no. 5. pp. 41-51.

13. Ageev N.D., Goroshin S.V., Zolotko A.N., Poletaev N.I. Skorost' stacionarnogo plameni v gazovzvesyah alyuminiya [Stationary flame velocity in aluminum gas suspensions]. Combustion of Heterogeneous and Gas Systems. Chernogolovka, 1989. pp. 83-85.

14. Poletaev N.I. Svyaz' skorosti rasprostraneniya pylevogo plameni s rezhimom goreniya chastic goryuchego [Relationship between the speed of dust flame propagation and the combustion mode of fuel particles]. Physics of Combustion and Explosion, 2016, vol. 52, no. 6. - pp. 60-69.

15. Egorov A.G. O skorosti rasprostraneniya plameni v aerovzvesi chastic alyuminiya [On the speed of flame propagation in air suspension of aluminum particles]. Physics of Combustion and Explosion 2020, vol. 56, no. 1 , pp. $48-58$.

\section{Об авторах}

Богомолов Ярослав Эдуардович (Пермь, Россия) - аспирант кафедры «Ракетно-космическая техника и энергетические системы» ФГАОУ ВО ПНИПУ (614990, г. Пермь, Комсомольский пр., д. 29, e-mail: bogomolov200@yandex.ru).

Малинин Владимир Игнатьевич (Пермь, Россия) - доктор технических наук, профессор кафедры «Ракетно-космическая техника и энергетические системы» ФГАОУ ВО ПНИПУ (614990, г. Пермь, Комсомольский пр., д. 29, e-mail: malininvi@ mail.ru).

\section{About the authors}

Iaroslav E. Bogomolov (Perm, Russian Federation) - PhD Student of Rocket and Space Engineering and Power Generating Systems Department, Perm National Research Polytechnic University (29, Komsomolsky av., Perm, 614990, Russian Federation; e-mail: bogomolov200@yandex.ru).

Vladimir I. Malinin (Perm, Russian Federation) - Doctor of Technical Sciences, Professor of Rocket and Space Engineering and Power Generating Systems Department, Perm National Research Polytechnic University (29, Komsomolskiy av., Perm, 614990, Russian Federation; e-mail: malininvi@ mail.ru). 